\title{
LA INFLUENCIA DEL CONTROL PREVENTIVO EN EL DISEÑO NORMATIVO DEL RÉGIMEN PRESIDENCIAL CHILENO
}

\section{The influence of preventive control in the legal system design of Chilean presidentialism}

\author{
FELIPE MELÉNDEZ ÁVILA' \\ Universidad Mayor (Chile) \\ felipe.melendez@umayor.cl
}

\section{Resumen}

El presente trabajo aborda el Tribunal Constitucional chileno (TC) en su contexto histórico y doctrinal, de manera tal de comprender el sentido y alcance del control preventivo de constitucionalidad de las leyes en el diseño normativo promovido por la Constitución de 1980. Se mostrará que buena parte del sentido actual del TC se debe al diagnóstico crítico identificado por los redactores de la Carta de 1980, no solo respecto del primer Tribunal Constitucional, sino que, por sobre todo, del sistema institucional articulado bajo la Constitución de 1925. De ahí que se argumente que pese existir fuertes continuidades normativas con el TC precedente, la versión actual se caracterizaría por otorgarle un sentido diverso, determinado en buena

1 Doctor en Derecho por la Universidad de Chile. Profesor de Derecho Constitucional y director de la Escuela de Derecho de la Universidad Mayor. 
medida por la desconfianza hacia la expresión de las mayorías políticas, especialmente por el temor al desborde gubernamental en la función legislativa, en el marco de un régimen presidencialista de gobierno.

\section{Palabras clave}

Control preventivo; función legislativa; presidencialismo; Tribunal Constitucional; Constitución; Chile.

\section{Abstract}

This paper addresses the Chilean Constitutional Court in its regulatory context, so as to understand the meaning and scope of preventive control of constitutionality of laws in the normative design promoted by the Constitution of 1980. It appears that much of the current sense of TC is due to the critical diagnosis identified by the drafters of the Charter of 1980, not only for the first Constitutional Court, but, above all, the institutional system articulated in the Constitution of 1925 . Hence it is argued that despite existing strong continuities regulations with the preceding Constitutional Court, the current version is characterized by granting it a different sense, determined largely by distrust expression of political majorities, especially fear of government overflow in the legislative function in the context of a presidential system of government.

\section{Keywords}

Preventive control; legislative function; presidentialism; Constitutional Court; Constitution; Chile. 


\section{SUMARIO}

I. INTRODUCCIÓN. II. UN DIAGNÓSTICO COMPARTIDO: LA DEBILIDAD DE LAS PRERROGATIVAS LEGISLATIVAS DEL PRESIDENTE BAJO LA CONSTITUCIÓN DE 1925: 1. El primer Tribunal Constitucional en Chile: żtribunal de conflictos o defensor de las prerrogativas presidenciales? III. EL TRIBUNAL CONSTITUCIONAL EN LA CONSTITUCIÓN DE 1980: UN DIAGNÓSTICO CRÍTICO RESPECTO DE LA INSTITUCIONALIDAD TODA: 1. La concepción de forma de Estado en la Constitución de 1980: una "democracia autoritaria y protegida»: 1.1. La «democracia autoritaria» y fortalecimiento de la forma de gobierno presidencialista. 1.2. La «democracia protegida" y el temor al desborde gubernamental. 2. La Constitución de 1980 y la instauración del segundo Tribunal Constitucional: 2.1. El control preventivo de constitucionalidad de las leyes: continuidad y cambio. IV. LA EVOLUCIÓN NORMATIVA DEL TRIBUNAL CONSTITUCIONAL Y DEL CONTROL PREVENTIVO TRAS EL RETORNO A LA DEMOCRACIA: 1. La reforma de 2005 y la eliminación de los «enclaves autoritarios»: ¿̇un nuevo Tribunal Constitucional? V. CONCLUSIONES. BibLIOGRAFÍA.

\section{INTRODUCCIÓN}

La doctrina chilena ha señalado mayoritariamente que el control preventivo de constitucionalidad de la legislación convierte al Tribunal Constitucional en una suerte de árbitro entre los poderes públicos, destinado a evitar conflictos entre el presidente de la República y el Congreso Nacional. Sin embargo, en el presente trabajo ofreceremos una interpretación distinta, que pone en evidencia la funcionalidad de esta modalidad de control con un determinado diseño normativo: el régimen presidencialista.

En primer término abordaremos el origen de esta modalidad de control en Chile en la Constitución de 1925, tras la reforma constitucional de 1970, que estableció el primer Tribunal Constitucional. Se destaca el particular contexto en el cual fue introducido, ya que este se enmarcó dentro de un cambio mayor destinado a establecer fuertes limitaciones al Congreso Nacional en la función legislativa, de manera de asegurar la posición institucional del presidente de la República en el proceso de formación de la ley. En tal sentido, el 
Tribunal Constitucional, por medio del control preventivo, pasó a jugar el rol de órgano de control de los límites establecidos a la actividad parlamentaria.

Y en segundo término, se abordará el restablecimiento de esta modalidad de control bajo la Constitución de 1980, Carta Fundamental vigente hasta nuestros días. Se mostrará el diagnóstico crítico respecto al orden precedente, para luego apreciar los elementos de continuidad y cambio que experimentó el control preventivo en el marco de la forma de gobierno presidencialista, diseño que se ha mantenido sin mayores cambios tras el retorno a la democracia, en marzo de 1990.

De esta manera, el presente trabajo pretende ofrecer una interpretación que sea capaz de articular la relación entre la justicia constitucional, a través del control preventivo, y el presidencialismo como forma de gobierno. Para mostrar tal cuestión se realizará una revisión tanto histórica como doctrinaria de las disposiciones constitucionales, a fin de dar cuenta de la existencia de este diseño normativo, que torna funcional el control preventivo al mantenimiento de determinada forma de gobierno. Es por ello que no será objeto de este trabajo la revisión jurisprudencial, la que será materia de un trabajo posterior, ya que a través de este artículo se pretende dejar sentada la existencia del particular diseño normativo en el constitucionalismo chileno.

\section{UN DIAGNÓSTICO COMPARTIDO: LA DEBILIDAD DE LAS PRERROGATIVAS LEGISLATIVAS DEL PRESIDENTE BAJO LA CONSTITUCIÓN DE 1925}

La Constitución de 1925 tuvo dentro de sus finalidades poner término a la práctica parlamentaria de la forma de gobierno, estableciendo límites a la acción del Congreso en la conducción gubernamental. Para ello propició una mayor separación de poderes, de forma tal de dotar de más autonomía al órgano ejecutivo. Es así que entre las diversas medidas, se estableció, por un lado, la incompatibilidad entre los cargos de ministro de Estado con el de senador y diputado, y por otra, una clara separación de funciones en favor del primer mandatario, a través de la supresión de las leyes periódicas en cuanto mecanismo político de los parlamentarios, al establecerse la aprobación automática del proyecto de ley de presupuesto del ejecutivo, frente a la negativa del Congreso de despacharlo antes de que debiera comenzar a regir (Heise, 1974: 454).

En este contexto de limitaciones a la acción del Congreso Nacional, se estableció por primera vez en el constitucionalismo chileno, el control judicial de constitucionalidad de las leyes. Paradojalmente, pese a estar adscrito a la tradición del derecho civil (Merryman, 1995: 15-23), en este ámbito siguió 
parcialmente el modelo de control de constitucionalidad norteamericano. En efecto, radicó este mecanismo solo en la Corte Suprema - estableciendo un control concentrado, y no de carácter difuso- bajo la modalidad represiva o a posteriori, vale decir, sobre leyes vigentes, por vía incidental, cuyo ejercicio podía traer aparejado como sanción sólo la inaplicabilidad del precepto que resultare contrario a la Constitución, con efecto inter partes y, por tanto, sino efecto derogatorio erga omnes.

Una vez que la Constitución entró en vigencia, a finales de 1932, los límites establecidos al Congreso en favor del presidente comenzaron a ser paulatinamente traspasados, a través de diversas prácticas políticas de los parlamentarios, tales como las leyes misceláneas, las cuales se caracterizaron por invadir funciones propias del primer mandatario, principalmente, en materias de índole financiera (Tapia, 1960: 41-46). Es así que en 1943 se promovió una reforma a la Constitución destinada a extender aún más las limitaciones a la acción del parlamento con ocasión del ejercicio de la función legislativa, la que finalmente se tradujo en la ampliación de las materias de iniciativa exclusiva del presidente, como en la posibilidad de decretar pagos no autorizados por ley. Correlativamente, se plasmó la restricción de los parlamentarios de influir positivamente en materia de gasto, estableciendo que solo podrían aceptar, disminuir o rechazar lo que hubiese sido propuesto por el primer mandatario, quedando vedado la facultad de poder crear o aumentar, tal como venía ocurriendo hasta esa fecha.

Sin embargo, pese a la ampliación de los límites establecidos en favor del presidente, estos continuaron siendo transgredidos por el Congreso Nacional a través de diversas prácticas, morigerando, consecuencialmente, la forma de gobierno diseñada en la Constitución de 1925 (Meléndez, 2010: 24). Ello era posible debido a la inexistencia de un órgano encargado de hacer eficaz dichas limitaciones (Aragón, 1987: 17-18). Si bien es cierto la Corte Suprema contaba con la inaplicabilidad, en la práctica, esta habría sido utilizada tímidamente, ya que el máximo tribunal se habría negado sistemáticamente a fallar cuestiones de forma o procedimentales, tales como la intromisión en facultades legislativas del presidente por parte del Congreso (Nogueira, 1996: 312), limitándose, por el contrario, a fallar solo cuestiones de fondo o materiales, fundamentando su posición en el principio de separación de poderes (Bertelsen, 1969: 165-171).

De esta manera, durante la década de 1960 se comenzó a realizar un diagnóstico crítico en torno al rol que estaba ejerciendo el Congreso Nacional en la función legislativa, la que, al menos normativamente, estaba diseñada para el predominio del primer mandatario. Como también, respecto al limitado papel desempeñado hasta ese entonces por la Corte Suprema, en cuanto 
órgano destinado a hacer efectivo el principio de supremacía constitucional (Cumplido, 1964: 71).

\section{EL PRIMER TRIBUNAL CONSTITUCIONAL EN CHILE: ¿̇TRIBUNAL DE CONFLICTOS O DEFENSOR DE LAS PRERROGATIVAS PRESIDENCIALES?}

Durante la presidencia de Frei Montalva persiste la necesidad de reforzar las prerrogativas presidenciales, como la de establecer un órgano encargado de controlar que las nuevas atribuciones fuesen respetadas por el Congreso Nacional. En primer lugar, porque se contempló la creación de un Tribunal Constitucional, independiente del Poder Judicial, a la usanza de los países de la tradición europeo-continental. Y en segundo lugar, porque no se pensó potenciar el control represivo, sino más bien, instaurar uno de carácter preventivo, de manera de evitar que el Congreso se excediera en sus prerrogativas durante el proceso de formación de las leyes. De esta forma, el control represivo seguiría en manos de la Corte Suprema.

La instauración del Tribunal Constitucional fue retomada en 1969, aunque inmersa dentro de un paquete de reformas mayor, destinado a fortalecer la posición institucional del presidente, en desmedro del Congreso Nacional, aprobado finalmente a través de la Ley 17.284 de 1970. En tal sentido, «en general, se acogió un planteamiento presidencial reiterado por los Presidentes Ibáñez, Jorge Alessandri y Frei, que acentuaba las finalidades originales de la Constitución de 1925» (Carrasco, 2002: 194). Esto es, consolidar un régimen presidencialista de gobierno.

En efecto, dentro de las modificaciones promovidas en favor del Ejecutivo, en el marco de la función legislativa, es posible mencionar la consagración constitucional de los decretos con fuerza de ley, la ampliación de las materias de iniciativa exclusiva del presidente, la facultad de dictar urgencias (anteriormente radicas en las Cámaras del Congreso Nacional), como la limitación a la formulación de indicaciones de los proyectos de ley, cuando estas no tratasen sobre ideas matrices o fundamentales del proyecto, bloqueando, de esta manera, las denominadas leyes misceláneas (Carrasco, 2002: 186).

La doctrina destaca dos prerrogativas particulares: la iniciativa exclusiva presidencial y la introducción de la institución de las ideas matrices como exigencia para la enmienda de un proyecto de ley, ambos antecedentes directos del régimen presidencial chileno actual. Como destacan los autores, «la reforma constitucional de 1970 tuvo el propósito, con decisión política y discusiones jurídico-institucionales ricas en argumentos, inhibir una serie de prácticas legislativas estimadas impropias, que esta- 
ban dañando los cimientos mismos de nuestra democracia» (Fermandois y García, 2009: 308).

De esta manera, bajo el contexto de una reforma presidencialista de la forma de gobierno aparece el primer Tribunal Constitucional chileno, lo que explica no solo su particular conformación e independencia, sino que sus atribuciones. En efecto, este quedó conformado por cinco miembros, tres de ellos designados por el presidente con acuerdo del Senado, y los dos restantes por la Corte Suprema de entre sus miembros. Duraban cuatro años en sus funciones y podían ser reelegidos. En cuanto a su funcionamiento, era necesaria la concurrencia de, a lo menos, tres de sus miembros y sus acuerdos se adoptarían por la mayoría de ellos.

No deja de llamar la atención la particular composición del primer Tribunal Constitucional, y que se enmarcaría dentro del sentido de su establecimiento, vinculado al reforzamiento de la forma de gobierno presidencialista. En primer lugar, atendido que la duración de los ministros era inferior a la de un período presidencial — seis años—, y equivalente tanto con el período de un diputado, como con la renovación parcial del Senado. Y en segundo lugar, producto a que el Tribunal gozaba de una autonomía relativa respecto de los demás poderes públicos, ya que los ministros de nombramiento presidencial eran susceptibles de ser removidos por este, con acuerdo del Senado. Estos lineamientos se ven reafirmados al momento de revisar sus atribuciones, particularmente, para la cual fue creado: el control preventivo.

Pues bien, la Constitución de 1925 — reformada en 1970 — le entregaba el control preventivo de constitucionalidad, con carácter facultativo, de los proyectos de ley y de los tratados sometidos a la aprobación del Congreso, que podía ejercerse hasta antes de su promulgación. Los legitimados activos para presentar la cuestión de constitucionalidad eran el presidente de la República, cualquiera de las Cámaras, o más de un tercio de sus miembros en ejercicio. Se dispuso un plazo expreso de diez días para que el Tribunal dictara sentencia, prorrogable por otros diez días más, por motivos graves o justificados. En cuanto al efecto de la interposición del requerimiento, este no suspendería la tramitación del proyecto de ley o del tratado, aunque establecía que la parte impugnada no podría ser promulgada hasta la expiración del plazo referido, salvo que se tratase de materias presupuestarias, militares, o vinculadas a los estados de excepción constitucional.

Respecto del efecto de las resoluciones del Tribunal Constitucional, la Constitución dispuso que no procedería recurso alguno, al tiempo que tratándose de la declaración de inconstitucionalidad, el proyecto no podría convertirse en ley. Asimismo, establecía un particular vínculo con la acción de inaplicabilidad que le correspondía conocer a la Corte Suprema, al disponer 
que no pudiera ser declarado inaplicable por el mismo vicio un precepto legal que hubiese sido declarado constitucional.

De las atribuciones entregadas al Tribunal Constitucional, sin lugar a dudas, la más relevante fue el control preventivo de constitucionalidad de las leyes, el cual se encuentra directamente vinculado con su sentido original, pese a que la versión más difundida ha sido aquella que lo concibe como tribunal de conflicto entre poderes (Frei, 1970: 48). Esta interpretación se funda, en buena medida, en lo señalado en el mensaje de la Presidencia que presentó el proyecto de ley que la contenía. De ahí que se sostenga que «no es aventurado concluir, por consiguiente, que la razón principal que llevó a Chile al establecimiento de un Tribunal Constitucional fue la necesidad de crear un procedimiento que impidiera la aprobación de normas contrarias a la Carta Fundamental. En otras palabras, la falta de un control preventivo de la constitucionalidad de las leyes» (Bertelsen, 1992: 205). Sin embargo, pese a que esta modalidad forma parte del control jurídico-político que realiza un Tribunal Constitucional, lo cierto es que su revisión requiere de un tratamiento especial.

En efecto, el establecimiento del control de constitucionalidad de las leyes, con carácter preventivo, se encuentra asociado a un diseño constitucional mayor, que se puede vincular bien con la forma de gobierno, o bien con la forma de Estado. De ahí que tome más fuerza aún aquellas interpretaciones que consideran al Tribunal Constitucional como órgano de control destinado a hacer eficaces las prerrogativas legislativas del presidente frente al Congreso Nacional, y no solo un órgano resolutor de conflictos entre colegisladores. Por lo demás, esta visión es la que más se asienta con el sentido general de la reforma de 1970, la cual se caracterizó, precisamente, por potenciar fuertemente las prerrogativas legislativas del primer mandatario.

Esta opinión es mantenida por los sectores de izquierda representados en el Congreso Nacional durante el proceso de reforma constitucional, ya que, estos creían que «el sistema presidencial era, a esa altura, suficientemente autoritario y el Congreso estaba demasiado limitado en sus facultades». Por tal motivo, estimaban que «no se requería, en consecuencia, fortalecer más aún las facultades del primero en desmedro del segundo». Es por ello que estos se opusieron a la creación del Tribunal Constitucional, por cuando este terminaría fortaleciendo al presidente de la República (Gómez, 1996: 36).

De igual manera, el presidente del primer Tribunal Constitucional sostiene que «más que jurídicas las ideas que condujeron a la creación del Tribunal Constitucional fueron predominantemente políticas, asignándole un importante rol como instrumento para el predominio de una política presidencialista». Asimismo, señala que "puesto que la Constitución de 1925, especialmente después de sus últimas reformas, era ciertamente presidencial, 
no es de extrañarse que los fallos del Tribunal, en su mayoría, dieran la razón al Ejecutivo. Es fácilmente demostrable que la gran parte de las reclamaciones presentadas ante él eran la consecuencia de actos en que el Congreso pretendía alzaprimar su criterio por sobre el del Jefe de Estado» (Silva, 2008: 24-25).

Esta interpretación también es compartida en la doctrina, ya que se ha sostenido que la creación del Tribunal Constitucional, «en la práctica política fortalecía al Presidente». Ello quedaba patente, además, por la particular prerrogativa de remoción con la cual contaban los órganos colegisladores. En efecto, «esta modalidad de remoción entregaba al Presidente un enorme poder sobre los ministros y dado que el plazo de duración en el cargo de Ministro era inferior al de los órganos que lo nombraban, se podía identificar un grado de compromiso de los Ministros y de la debilidad del Tribunal». Es así que «es evidente que los órganos que crearon este Tribunal en 1970 no quisieron perder el control del mismo y con ello le provocaron una clara debilidad» (Gómez, 1996: 36-39).

Con todo, atendida la corta duración del Tribunal Constitucional, si bien existieron tres fallos que le dieron la razón al Ejecutivo en materia de ideas matrices (Fermandois y García, 2009: 290-294), no resulta posible comprobar si la práctica del control preventivo habría respondido o no a este diseño. En efecto, el Tribunal entró en funciones el 10 de septiembre de 1971, cesando de facto tras el golpe de Estado del 11 de septiembre de 1973, vale decir, tras solo dos años desde su instalación. En su breve existencia, alcanzó a conocer solo diecisiete casos de constitucionalidad, ocho veces a requerimiento del presidente, tres a requerimiento de un grupo de senadores, en dos oportunidades por la Cámara de Diputados, y en dos ocasiones por el Senado (Andrade, 1996: 296).

Por su parte, cabe destacar que el momento en que entró en funciones el Tribunal Constitucional fue sumamente politizado, atendido el contexto de fuertes transformaciones estructurales promovidas por el gobierno de la Unidad Popular (Correa et al., 2005: 295-274) — lo que formaba parte de la «época de las planificaciones globales» (Góngora, 2006: 288-294)— existiendo gran efervescencia por cada decisión que este adoptaba (Andrade, 1996: 297). Con todo, la decisión más controvertida fue aquella que abordó el proyecto de reforma constitucional que fijaba las tres áreas de la economía, que sumió en un fuerte conflicto a los órganos colegisladores presidente-Congreso Nacional, donde el Tribunal Constitucional decidió declararse incompetente. De hecho, diversos autores han coincidido que esta decisión sería una de las causas del quiebre institucional de septiembre de 1973 (Silva, 2003: 13). 


\section{EL TRIBUNAL CONSTITUCIONAL EN LA CONSTITUCIÓN DE 1980: UN DIAGNÓSTICO CRÍTICO RESPECTO DE LA INSTITUCIONALIDAD TODA}

El golpe de Estado de 1973 representa una fecha clave en la historia institucional y constitucional de Chile. No solo porque puso término, a través de la fuerza, al gobierno de la Unidad Popular encabezado por el presidente Allende, sino que además por cuanto implicó la desarticulación total de la Constitución de 1925, con claros fines refundacionales. Si bien el Decreto Ley 1 estableció como finalidad de constitución de la Junta de Gobierno «restaurar la chilenidad, la justicia y la institucionalidad quebrantadas», el día 24 de septiembre — vale decir, a solo trece días después del golpe de Estado—, esta convocó a un grupo de abogados con la finalidad de elaborar un anteproyecto de nueva Constitución y sus leyes complementarias, lo que posteriormente se oficializó el 25 de octubre del mismo año (Carrasco, 2002: 222).

En efecto, el proyecto refundacional de la Junta Militar aspiraba a "corregir la trayectoria reciente del país; supuestamente los chilenos habríamos caído en el "desquiciamiento moral y económico", haciendo peligrar, incluso, "la seguridad interna y externa del país", y, más aún, la "subsistencia" de Chile como "Estado independiente"”, tal como reza en su declaración de principios (Correa et al., 2005: 284). En este sentido, «el golpe militar no solo se empecinó en contra del gobierno de la Unidad Popular, sino que pretendió disciplinar si es que no castigar o incluso anular todo el entramado político institucional que se venía gestando desde el siglo XIX», el cual se articulaba «en ideales republicanos, a la vez democráticos y liberales, que la sostenía» (Ruiz-Tagle, 2006: 130).

Esta idea refundacional fue esencial en el diseño institucional establecido en la Carta de 1980, la cual se inicia, precisamente, a partir de este diagnóstico crítico sobre la institucionalidad toda, formando parte de lo que se ha denominado la tercera etapa de las «Planificaciones Globales», ya que «se inicia a partir de entonces una reestructuración general de la economía, de la sociedad y del poder estatal: en cierto modo una "revolución desde arriba" " (Góngora, 2006: 294). Como se ha destacado, la Constitución fue diseñada «fundamentalmente mirando hacia el pasado a los problemas políticos-institucionales que se habían producido en Chile» (Barros, 2005: 220), como se verá a continuación.

El proyecto refundacional plasmado en la Constitución Política de 1980, tuvo como antecedente tres instancias de trabajo: la Comisión Constituyente, posteriormente denominada como Comisión de Estudios de la Nueva Constitución Política del Estado, y conocida popularmente como "Comisión Ortúzar»; el Consejo de Estado —órgano de carácter consultivo creado el año 
1976, y presidido por el expresidente Jorge Alessandri-que le correspondió pronunciarse respecto del anteproyecto elaborado por la Comisión de Estudios; y el Grupo de Trabajo designado por la Junta Militar, el cual comenzó a operar una vez que esta recibió el proyecto elaborado por el Consejo de Estado (Carrasco, 2002: 224-244).

De las tres instancias anteriormente señaladas, solo tenemos conocimiento fehaciente respecto de las dos primeras, a través de las actas que ellas dejaron tras de sí, toda vez que el Grupo de Trabajo no dejó registros conocidos. Como se ha destacado, «si bien las actas de estos cuerpos permiten penetrar de una manera que resulta fascinante en la forma de que un grupo de prominentes conservadores percibieron las instituciones y la redemocratización...», sin embargo, "no explican por qué o cuándo la Junta tomó la decisión política de promulgar una nueva constitución» (Barros, 2005: 214). Sin embargo, terminó primando la idea de la Comisión de Estudios —con claros tildes refundacionales - aunque con ciertas modificaciones relevantes introducidas por el Grupo de Trabajo organizado por la Junta Militar, previo a la promulgación del texto constitucional, sobre el cual, lamentablemente, no existen actas conocidas.

\section{LA CONCEPCIÓN DE FORMA DE ESTADO EN LA CONSTITUCIÓN DE 1980: UNA «DEMOCRACIA AUTORITARIA Y PROTEGIDA»}

Como pudimos apreciar, durante la época de formulación de la Carta del 80, está presente un diagnóstico crítico que trasciende al Tribunal Constitucional y que abarca a la institucionalidad político-constitucional toda, atendido el carácter fundacional emprendido por la Junta Militar. Dicha transformación institucional buscaba, según consta en comunicación del general Pinochet al presidente de la Comisión de Estudios, configurar «una nueva democracia, cuyas características más importantes he sintetizado bajo los términos de autoritaria, protegida, integradora, tecnificada y de auténtica participación social» (Pinochet, 1978: III). En respuesta, la Comisión de Estudios, reafirmando lo ya señalado anteriormente, sostuvo que «el $11 \mathrm{de}$ Septiembre de 1973 no sólo significó el derrocamiento de un Gobierno ilegítimo y fracasado, sino que representó el término de un régimen político-institucional definitivamente agotado y el consiguiente imperativo de construir uno nuevo» (Comisión, 1978: 2). Reafirmando el carácter refundacional como la particular noción de democracia promovida por Pinochet, la Comisión de Estudios se detuvo a analizar cada uno de sus aspectos, destacando, para los efectos de esta investigación, dos de ellos: la noción de «democracia protegida y autoritaria». 
Los autores han destacado las particularidades de la forma de Estado promovida por la Constitución de 1980, aunque no las han logrado diferenciar en los términos ideados por sus creadores. Es así que unos solo identifican la existencia de una "democracia protegida» (Godoy, 2003: 13-18), mientras que otros, si bien recogen ambas dimensiones, lo abordan como expresiones homologables (Garretón, 1989: 37). Sin embargo, esta distinción es fundamental para poder comprender la vinculación entre la forma de gobierno presidencial y el control preventivo practicado por el Tribunal Constitucional chileno, como veremos a continuación.

\subsection{La «democracia autoritaria» y fortalecimiento de la forma de gobierno presidencialista}

Para la "Comisión Ortúzar» se debía propiciar una «democracia autoritaria», lo que a su juicio "no quiere decir que sea arbitraria. Por el contrario, el ejercicio de la autoridad, dentro del marco de la Constitución y de la ley, constituye una garantía para las personas de que podrán ejercer sus derechos en un ambiente de armonía y seguridad». Ello se traduce en el reforzamiento del régimen presidencial, "como una autoridad fuerte, justa e impersonal, de carácter portaliano, en que el Presidente tendrá todos los atributos no sólo para conservar el orden público y preservar la seguridad nacional, sino para realizar una administración expedita, como lo requiere la naturaleza de los problemas de hoy, fundamentalmente técnicos y socioeconómicos» (Comisión, 1978: 167).

De igual manera, cabe destacar lo expresado por Jaime Guzmán, integrante de la Comisión de Estudios desde sus orígenes, quien desempeñó un rol fundamental en la génesis de la Constitución actual, no solo como partícipe de dicha instancia, sino que también a través de la redacción de documentos fundacionales de la Junta Militar, como la «Declaración de Principios del Gobierno de Chile» del 11 de marzo de 1974, así como de los discursos presidenciales claves (Cristi, 2000: 33).

Es así que Guzmán retoma las discusiones de la década de los sesenta, en orden a criticar la intromisión del Congreso Nacional en prerrogativas propias del presidente, pese a las diversas enmiendas llevadas a cabo a lo largo del siglo $\mathrm{xx}$. Al respecto sostuvo que «la función de gobernar es más técnica y compleja, y requiere de una coherencia y responsabilidad que sólo puede lograrse en el seno del Gobierno, pero no en la heterogeneidad de una asamblea parlamentaria» (Guzmán, 1979: 65). De ahí que destaca la importancia del trabajo de la Comisión de Estudios, en orden a fortalecer el presidencialismo chileno, expresión de la denominada «democracia autoritaria». 
En primer lugar, por medio del reemplazo del dominio legal mínimo por el dominio legal máximo, el que inspirado en la Constitución francesa de la Quinta República, delimita las materias para las cuales la Carta Fundamental exige de una ley. En segundo lugar, por la preeminencia entregada al primer mandatario en la tramitación de las leyes a través de la herramienta de veto, lo que posibilita que «sólo él pueda quebrar la exigencia normal de que toda ley deba contar con la aprobación mayoritaria del Congreso». En tercer lugar, por medio de la facultad entregada al presidente de disolver por una sola vez en su período la Cámara de Diputados. Si bien Guzmán comprende que la prerrogativa de disolver la Cámara era propia de los regímenes parlamentarios, estimaba que era necesaria su incorporación, ya que, a su juicio, «debe incorporarse al presidencialismo como un medio de zanjar posibles crisis políticas graves, teniendo presente que el hecho de que su ejercicio derive de inmediato en una lección general en todo el país (...), hará que su aplicación sea cauta y moderada, junto con servir de freno a posibles caprichos de la Cámara». Y, finalmente, el aumento del período presidencial a ocho años, al hacer coincidir su elección con la de los parlamentarios, al tiempo de suprimir las elecciones complementarias en caso de vacancia del cargo de senador o diputado. A su juicio, ello permite al gobierno "enfocar su gestión con mayor eficacia, mientras que el no verse abocado a constantes elecciones da más libertad a su acción y evita una permanente efervescencia política en el país» (Guzmán, 1979: 64-66). Todos elementos, que como queda en evidencia, dan cuenta de la «democracia autoritaria» proyectada para la futura Constitución.

\subsection{La «democracia protegida» y el temor al desborde gubernamental}

La Comisión de Estudios señaló que «no se trata de que la democracia tenga un tutor o protector sino de que se proteja a sí misma mediante adecuados instrumentos jurídicos que le dan vigor». En el ámbito orgánico, ello se traduce en «radicar las funciones de Gobierno, Legislativa, Judicial y Contralora, en órganos diversos e independientes entre sí y precisar la órbita de acción de cada uno de ellos, sin perjuicio de su adecuada interrelación». En este contexto, agrega, «el Tribunal Constitucional... tiene la inspiración básica de preservar y fortalecer la democracia» (Comisión, 1978: 14-20).

$\mathrm{Al}$ respecto, Guzmán sostiene que en vista del enfoque autoritario dado por el fortalecimiento del ejecutivo, «aconsejan el desarrollo de otros elementos de equilibrio de la facultad presidencial, que conviene diseñar en instancias más bien técnicas, y no en una voluntad política cuyo único contrapeso efectivo se logra al precio de arriesgar la eficacia de la gestión gubernativa». Y atendido el fuerte debilitamiento del Congreso Nacional, «aconseja el desarrollo de otros elementos de equilibrio de la facultad presidencial, que conviene 
diseñar en instancias más bien técnicas, y no en una voluntad política cuyo único contrapeso efectivo se logra al precio de arriesgar la eficacia de la gestión gubernativa» (Guzmán, 1978: 67-69). En otros palabras, hace ver la necesidad de instrumentos jurídicos que expresen una «democracia protegida», temerosa que este ejecutivo fortalecido termine desbordando los cauces institucionales.

Bajo esta concepción de la forma de Estado, cobra particular relevancia el Tribunal Constitucional, ya que para la Comisión de Estudios, este órgano presente en "casi todas las Constituciones» a nivel comparado, está llamado a velar por el «principio de supremacía constitucional y a resolver los conflictos de carácter jurídico-constitucional que surjan entre los diversos órganos del Estado y, especialmente, entre el Poder Ejecutivo y el Legislativo». Con todo, estiman necesario modificar su composición como ampliar sus atribuciones, en comparación con el primer Tribunal Constitucional. A su juicio, este se habría caracterizado por tener una composición preferentemente política, por sobre jurídica, aspecto que habría motivado el fracaso y desprestigio de ese Tribunal. Por tal motivo proponen, por una parte, una integración que «responda al carácter eminentemente jurídico y judicial de las altas y delicadas atribuciones que le competen». Para ello, propusieron que este se conformara por siete miembros, tres de ellos, ministros de la Corte Suprema designados por esta, dos abogados elegidos por la Corte Suprema, y un abogado designado por el presidente de la República. Vale decir, ningún nominado por el Congreso Nacional. Asimismo, que sus ministros tuvieran carácter inamovible, con una duración de seis años, renovables parcialmente cada tres. Por su parte, en cuanto a sus competencias, promovieron la ampliación del control preventivo facultativo a los proyecto de reforma constitucional, como la creación del control de las leyes orgánicas antes de su promulgación, aunque sin esbozar mayores explicaciones (Comisión, 1978: 245-249).

En este sentido, el Tribunal Constitucional toma particular relevancia, ya que este debe estar enfocado en resolver «los conflictos jurídicos que se susciten entre el Presidente de la República, por un lado, y el Congreso o la Contraloría, por el otro». Pero particularmente, «está llamado a dar vida a un instrumento de la máxima importancia para evitar eventuales desbordes gubernativos». Para ello resulta de capital importancia reformular este órgano tal y como había sido estructurado con la reforma de 1970. En efecto, sostienen que «la insatisfactoria experiencia del Tribunal Constitucional anterior hace evidente la necesidad de conformarlo sobre la base de un origen eminentemente judicial, y no político» (Guzmán, 1979: 68).

Complementario a estos instrumentos jurídicos, se estimó otorgarle a las FF. AA. un rol fundamental, por cuanto la Comisión sostuvo que ellas «tienen una alta misión que cumplir y una trascendental responsabilidad en los destinos de la Patria». Esto debido a que «demostraron ser la gran reserva moral del 
país, sin la cual no habría podido tener lugar la legítima rebelión del pueblo de Chile en contra del régimen que, desconociendo su ser nacional esencialmente libertario y altivo, quiso someterlo a un yugo totalitario foráneo». De ahí que sostienen que «no podría, pues, la nueva institucionalidad prescindir de esta realidad que asigna a las Fuerzas Armadas y de Orden un rol preponderante en la vida nacional». Es por ello que argumentan que estas «deben necesariamente estar presentes en todo cuanto atañe a los supremos intereses del país y al desarrollo que éste debe tener para lograr su destino como Nación soberana y libre» (Comisión, 1978: 267).

Al respecto Guzmán resaltaba la creación del Consejo de Seguridad Nacional, por cuanto, a través de él, "ha de introducir orgánicamente en el esquema constitucional el papel activo que en éste deben tener las Fuerzas Armadas y de Orden». De forma coherente con la noción de «democracia protegida», el autor no era partidario de otorgarle un poder de veto frente a decisiones de reforma constitucional, legales o administrativas, atendido

los graves peligros que podrían derivarse de una fórmula semejante, tanto por que se rompería la armonía de un esquema constitucional al consagrarse un poder que estaría por encima del Jefe de Estado y demás autoridades establecidas por la Constitución, cuanto porque ello arrastraría a las Fuerzas Armadas y de Orden al campo de la política contingente de un modo incompatible con su naturaleza castrense, a la vez que las haría corresponsables, por omisión, de toda medida que resultara negativa y que no hubiese sido vetada en su oportunidad, con el riesgo consiguiente de afectar el prestigio de Instituciones llamadas a ser la reserva última o suprema de la nacionalidad (Guzmán, 1979: 69-75).

De esta manera, los medios de control de la voluntad mayoritaria como de la «democracia autoritaria» quedarían en manos de los referidos mecanismos jurídicos establecidos por la propia Constitución.

En síntesis, es posible apreciar que la concepción de forma de Estado en la Constitución de 1980, promovía una "democracia autoritaria» caracterizada por el fortalecimiento del presidente, particularmente, respecto del Congreso Nacional. Asimismo, una "democracia protegida», conformada por diversos instrumentos jurídicos destinados a evitar el desborde gubernamental, vale decir, los eventuales excesos del nuevo régimen presidencialista que se pretende establecer, operando como un contrapeso de la forma de gobierno, de forma tal de «amarrar el futuro por temor al pasado» (Barros, 2005: 270). A ambas nociones de "democracia», se añadía un tercer elemento, esta vez fáctico, que de cierta manera pasa a operar como una suerte de última ratio, conformado por el decisivo rol asignado a las FF. AA. de ser garantes del orden institucional de la República. 


\section{LA CONSTITUCIÓN DE 1980 Y LA INSTAURACIÓN DEL SEGUNDO TRIBUNAL CONSTITUCIONAL}

La Carta de 1980 fue aprobada por Pinochet, y por la totalidad de los miembros de la Junta, promulgándose a través del Decreto Ley 3464, de fecha 8 de agosto de 1980. Asimismo, se dictó el Decreto Ley 3465, de igual fecha, convocando a plebiscito para la aprobación del texto por la ciudadanía, entrando en vigencia el 11 de marzo de 1981. Sin embargo, atendido el carácter autocrático del régimen, todo el proceso de ratificación ciudadana fue objeto de una fuerte manipulación, lo que no hace sino confirmar las críticas respecto a su legitimidad de origen.

En efecto, «el plebiscito, efectuado el 11 de septiembre de 1980, careció de garantías mínimas para las opiniones discrepantes, y su resultado final favoreció ampliamente al Gobierno, como se había previsto» (Urzúa, 1992: 728). Pese a que fue aprobado con el 67,04\% contra el 30,19\% de los votos, su irregularidad fue manifiesta, por cuanto «no se contó con registros electorales, y tanto la campaña de 30 días como los comicios se efectuaron bajo estado de emergencia, estando facultado todo ese tiempo el gobierno para relegar, detener y exiliar; el acceso a los diarios fue parcial al oficialismo, y en cuanto a la televisión le fue absolutamente vedada a los opositores» (Correa et al., 2005: 223).

Como era de esperarse la entrada en vigencia de la Constitución fue parcial, ya que permitía el mantenimiento del régimen militar por lo menos ocho años más. Por tal motivo, mal podría argumentarse que el texto estaba pensado para limitar a las FF. AA., toda vez que conservaron intactas sus atribuciones. Ello por cuanto la Carta de 1980 se conformaba por disposiciones permanentes y por disposiciones transitorias. Esta distinción es fundamental para comprender la entrada en vigencia de la Constitución en el contexto de un régimen autocrático, ya que si bien «durante esta etapa se aplicaron la mayor parte de las disposiciones constitucionales» (Carrasco, 2002: 251-271), tras de ellas «se conservaba la estructura real del poder dictatorial, reforzada por el andamiaje autoritario de las disposiciones transitorias» (Barros, 2005: 263).

Bajo este contexto, la Carta Fundamental de 1980 reestableció el Tribunal Constitucional, con una composición diversa y con atribuciones más amplias, de forma coherente con la concepción de forma de Estado promovida por sus redactores, estructurada como una «democracia autoritaria y protegida" - prevista en el articulado permanente- destinada a regir para la democracia futura, y no, como podría pensarse, para controlar al régimen autocrático, estructurado bajo las disposiciones transitorias, tal como se señaló anteriormente. 
En efecto, en cuanto a su composición, si se le compara con el creado en la década de 1970, aumentó de cinco a siete miembros, pero de una manera diversa a la planteada en los anteproyectos elaborados por la Comisión de Estudios y el Consejo de Estado. Se estableció que este estaría conformado por tres ministros de la Corte Suprema, elegidos por esta, un abogado designado por el presidente de la República, un abogado elegido por el Senado, por la mayoría de votos de los senadores en ejercicio, y por dos abogados elegidos por el Consejo de Seguridad Nacional. Por su parte, se aumentó la duración del cargo de cuatro a ocho años con renovaciones parciales cada cuatro, y se les otorgó expresamente el carácter de inamovibles (Carrasco, 2002: 249).

Al respecto, cabe destacar, en primer lugar, la incorporación del Consejo de Seguridad Nacional como órgano encargo de nombrar a dos de los ministros del Tribunal Constitucional, prerrogativa que fue introducida por el Grupo de Trabajo de la Junta Militar, previo a la promulgación del texto constitucional, sobre el cual, lamentablemente, no existen actas conocidas. Al respecto se ha señalo que el proyecto final habría morigerado la integración «judicialista» propuesta por la Comisión de Estudios, a través de la introducción más "política» (Zúñiga, 2002: 64). En segundo lugar, que los dos miembros nombrados por los poderes democráticos — presidente y Senadodebían haberse desempeñado como abogados integrantes de la Corte Suprema por lo menos tres años, requisito no exigido para los miembros designados por el COSENA.

En cuanto al control preventivo - facultativo y obligatorio- se ha señalado que esta modalidad «está destinada a frenar a la institución que se cree más peligrosa para la Constitución: las Cámaras del Congreso" (Gómez, 1996: 144). Ello sería "concordante con la "racionalización" del Congreso Nacional», promovida por el constituyente autoritario de 1980 (Zúñiga, 2002: 77). Sin embargo, como veremos a continuación, esta caracterización es parcialmente correcta, ya que, como argumentaremos a continuación, resulta necesario distinguir ambas modalidades de control, toda vez que ellas responden a dos lógicas distintas de la concepción de forma de Estado establecida en la Constitución chilena.

\subsection{El control preventivo de constitucionalidad de las leyes: continuidad y cambio}

El control de constitucionalidad de las leyes, en términos generales, mantuvo bastante continuidad respecto del diseño normativo previsto por la Carta de 1925, por cuanto la Constitución de 1980 entrega el control represivo, por vía incidental y con efectos relativos, a la Corte Suprema, mientras que el control preventivo queda en manos del Tribunal Constitucional. De hecho, 
dispone - al igual que el texto precedente - un fuerte vínculo entre la modalidad a priori con la a posteriori, al establecer que el precepto estimado constitucional, no podrá ser declarado inaplicable por el mismo vicio materia de la sentencia, lo que la doctrina ha denominado «sello de constitucionalidad» (Paredes, 2011: 165-172). Sin embargo, a la modalidad facultativa —expresión de la «democracia autoritaria»— se añadió la obligatoria, no prevista en el texto precedente, pero que responde plenamente a la concepción de forma de Estado de "democracia protegida», como veremos a continuación.

a) El control preventivo facultativo como expresión de la «democracia autoritaria»

Una importante continuidad es posible constatar con ocasión del control preventivo facultativo, ya que sigue prácticamente los mismos lineamientos del diseño establecido en la Carta de 1925 con la reforma de 1970, esto es, como mecanismo destinado a hacer respectar las prerrogativas legislativas del presidente de la República frente al Congreso Nacional, en el marco del proceso de formación de las leyes. En el caso de la Constitución de 1980 esto es más patente aún, atendido la concepción de forma de Estado, caracterizada por una "democracia autoritaria», con un reforzamiento aún más relevante de las prerrogativas del primer mandatario.

De esta manera, por medio de la modalidad facultativa, el Tribunal Constitucional cuenta con la atribución de resolver las cuestiones de constitucionalidad que se presenten respecto de proyectos de ley, como de tratados internacionales sometidos a la aprobación del Congreso. A ellas, se adiciona la prerrogativa de resolver las cuestiones de constitucionalidad suscitadas durante la tramitación de los proyectos de reforma constitucional, como una suerte de lección aprendida luego de la actitud adoptada por el Tribunal Constitucional en el caso de las tres áreas de la economía, donde este se declaró incompetente de resolver el conflicto, en el marco de una reforma constitucional, tal como se señaló anteriormente.

En cuanto a los órganos legitimados para presentar el requerimiento ante el TC, la Constitución contempla al presidente de la República, los presidentes de cualquiera de las Cámaras del Congreso Nacional, o una cuarta parte de sus miembros en ejercicio, posibilitando, de esta manera, $-\mathrm{y}$ al igual que en el caso del primer Tribunal Constitucional — su utilización por parte de las minorías políticas. Todos ellos gozan de una facultad bastante amplia, ya que están habilitados para presentar requerimientos desde el minuto que se inicia el proceso legislativo, esto es, previo a que se haya llevado a cabo cualquier tipo de deliberación, hasta que se encuentre pendiente la promulgación por parte del primer mandatario. En el caso de los tratados internacionales, el 
plazo se extiende hasta la remisión de la Cámara de origen de la comunicación que informa la aprobación del tratado al ejecutivo. Con todo, cabe señalar que la propia Carta Fundamental establece que en caso alguno podrán ser presentados requerimientos después del quinto día del despacho del proyecto - por parte del Congreso Nacional—o de la señalada comunicación.

Cabe destacar que la Constitución establece un plazo acotado para la resolución del requerimiento del Tribunal Constitucional, como una manera de morigerar su intervención en pleno proceso legislativo. En efecto, se contemplan diez días desde que este ha sido presentado, prorrogable por diez días más por motivos graves o calificados. Si bien su interposición no suspende el trámite legislativo, las disposiciones impugnadas no podrán convertirse en ley hasta que el Tribunal se haya pronunciado, excepto cuando se trate de proyectos de ley de presupuesto o del proyecto de declaración de guerra propuesto por el presidente de la República. En caso de acoger el requerimiento, las disposiciones declaradas inconstitucionales no podrán convertirse en ley, en cambio, en el evento de ser rechazado, el procedimiento legislativo seguirá su curso normal.

En síntesis, se trata de una modalidad de control que guarda bastantes semejanzas con la establecida en la reforma de 1970, pero que cobra una relevancia mayor en el contexto de la Constitución actual, producto del fuerte reforzamiento de la forma de gobierno presidencialista, esta vez, bajo el diseño normativo de "democracia autoritaria», tal como vimos anteriormente.

b) El control preventivo obligatorio como expresión de la «democracia protegida»

Una de las mayores innovaciones en materia de control de constitucionalidad de la ley es, sin lugar a dudas, la introducción del control preventivo obligatorio, no previsto en el primer Tribunal Constitucional, y que responde a la concepción de forma de Estado adoptada por nuestra Carta Fundamental: la «democracia protegida». Esta modalidad se inserta dentro de los instrumentos jurídicos destinados a evitar el desborde gubernamental, por lo que su función se explica, en buena medida, por la existencia de distintos tipos de normas jurídicas, que tiene como característica principal requerir para su creación, modificación o derogación, de quorum de carácter supramayoritarios.

En efecto, la Constitución establece como primera atribución del Tribunal Constitucional, el ejercer el control preventivo obligatorio respecto de las leyes interpretativas de la Constitución, de las leyes orgánicas constitucionales (LOC), y tras las reformas de 2005, sobre los tratados internacionales que contengan materias propias de estas últimas. El momento del control es desde que estos se encuentren totalmente tramitados por el Congreso Nacional, 
estando pendiente su promulgación por parte del primer mandatario, y, por tanto, la sanción o veto del presidente de la República (Nogueira, 1996: 328). La Cámara de Origen cuenta con un plazo de cinco días para remitir el proyecto al Tribunal Constitucional.

De las normas sujetas a la modalidad obligatoria, destacan las leyes orgánicas constitucionales, ya que desempeñan un rol clave en el diseño normativo en la concepción de la forma de Estado de la Constitución chilena, atendido el carácter complementario que tienen respecto de las disposiciones constitucionales (Bulnes, 1984: 239). Ello debido a que, con la sola excepción del COSENA, cada órgano constitucional va acompañado por una de ellas. Pero también abarcan aspectos dogmáticos, vinculados a la regulación de los derechos políticos, la libertad de enseñanza, y al derecho de propiedad, a propósito de las concesiones mineras. $\mathrm{Al}$ respecto, se ha sostenido que "tales reglas expresan la intención del Constituyente de limitar la acción del legislativo ordinario respecto de ciertas materias definidas como "importantes" y obligar a altos acuerdos para la dictación, derogación o reforma de una LOC». Con ello, «se vuelve más difícil legislar sobre estas materias, si no hay voluntades políticas más que las mayoritarias» (Gómez, 1996: 169).

Cabe destacar que en el anteproyecto de la Comisión de Estudios sometido a la aprobación de Pinochet, y por este, al Consejo de Estado, se dispuso que el quorum fuera de mayoría absoluta, criterio que este órgano ratificó. No fue sino en el seno del Grupo de Trabajo articulado bajo el alero de la Junta Militar, que el quorum fue aumentado a las $3 / 5$ partes de los diputados y senadores en ejercicio. Lamentablemente, como la tercera instancia de trabajo no dejó actas conocidas de su labor, no conocemos las motivaciones para el aumento drástico del quorum, el que quedó igual que para las leyes de reforma constitucional. Como es lógico este altísimo quorum, también denominado supramayoritario por cuanto va más allá de la regla de la mayoría aspecto característico de una democracia (Sierra, 2011: 19-25), estaba destinado a operar una vez se produjera el retorno a la democracia, con la instalación del Congreso Nacional, y no durante la vigencia del régimen militar.

Sin embargo, el alto quorum de las LOC logró ser parcialmente morigerado tras las negociaciones realizadas entre el Gobierno y la oposición de la época, que posibilitaron las primeras reformas a la Constitución, plebiscitadas el año 1989. En efecto a través de esta enmienda, se rebajó el quorum de 3/5 a 4/7 partes de los senadores y diputados en ejercicio. Como ha destacado, inicialmente se propuso este se rebajara a la mayoría absoluta, tal como regía en el modelo francés. Sin embargo, la Junta Militar propuso que quedará en un quorum mayor, conformado por las $4 / 7$, el que subsiste hasta la actualidad (Carrasco, 2002: 229). 
En síntesis, el control preventivo obligatorio mirado aisladamente no se aleja de la actividad propia que realiza un Tribunal Constitucional, ya que la justicia constitucional, por esencia, participa de la función legislativa, por lo que mal podría calificarse de buenas a primeras como un control meramente político. Sin embargo, la modalidad preventiva tiene especificidades que suelen ir más del resguardo del principio de supremacía constitucional.

En el caso de la Constitución chilena el control preventivo obligatorio se inserta dentro de los diversos instrumentos jurídicos propios de la concepción de forma de Estado de «democracia protegida» establecida por ella, particularmente las leyes de quorum supramayoritario, y cuya finalidad primordial es evitar el desborde gubernamental en la función legislativa. De ahí que no solo se contemplen materias de ley con quorum que exceden la regla de la mayoría, sino que a su vez, deban ser objeto de control preceptivo por parte del Tribunal Constitucional.

\section{LA EVOLUCIÓN NORMATIVA DEL TRIBUNAL CONSTITUCIONAL Y DEL CONTROL PREVENTIVO TRAS EL RETORNO A LA DEMOCRACIA}

Con el retorno a la democracia, comenzó a operar la concepción de forma de Estado diseñada por la Constitución de 1980, la cual ha gozado de una importante continuidad en el tiempo, sin perjuicio de lo cual, ha sido objeto de múltiples reformas (Carmona, 2014: 57-81), dentro de las cuales cabe destacar las de 1989 y de 2005, ya que han permitido morigerar este diseño, aunque sin modificarlo en sus rasgos fundamentales, como veremos a continuación.

La primera reforma a la Constitución a destacar, aconteció previo al advenimiento de la democracia, la cual pese a que no logró modificar las atribuciones ni composición del Tribunal Constitucional, destacó por haber morigerado la forma de Estado de democracia «autoritaria» y "protegida». En efecto, a través de ella se suprimió la facultad del primer mandatario de poder disolver las sesiones de la Cámara de Diputados, quedando un poco más equilibrado el diseño presidencial original, morigerando la concepción «autoritaria» de democracia. La acepción "protegida», por su parte, sufrió cambios, pero no en sus aspectos sustanciales, sin perjuicio de lo cual, destaca la modificación en la composición del Consejo de Seguridad Nacional, el que quedó conformado por igual cantidad de miembros civiles como militares, aunque sin generar mayores transformaciones en sus atribuciones; la supresión del art. 8, anteriormente señalado; como también la modificación del quorum de 
las leyes orgánicas constitucionales rebajándose de $3 / 5$ a 4/7 de los diputados y senadores en ejercicio (Andrade, 2002: 199-241).

La segunda reforma relevante fue la llevada a cabo el año 2005, esto es, tras quince años del retorno a la democracia, donde nuevamente la forma de Estado establecida en la Constitución fue objeto de importantes cambios, aunque nuevamente, sin lograr alterar los aspectos centrales de su diseño normativo. Estas enmiendas se insertaron dentro de una reforma mayor que tuvo dentro de sus finalidades primordiales poner término a los denominados «enclaves autoritarios» (Garretón, 1989: 51-63), expresión de la particular concepción de forma de Estado diseñada por los redactores de la Constitución de 1980. Ello quedó de manifiesto — en términos simbólicos- con el cambio de la firma de la Constitución, suprimiendo la del general Pinochet, y sustituyéndola por la del presidente de la República Ricardo Lagos.

Es así que se introdujeron cambios en la denominada «democracia autoritaria» — expresada en el régimen presidencialista—, entregando mayores herramientas de contrapeso al Congreso Nacional frente al primer mandatario. En este sentido, cabe destacar, respecto de la Cámara de Diputados la facultad de exigir al presidente, a través de sus ministros, respuestas a preguntas planteadas por la Cámara de manera fundada; la constitucionalización de la práctica de la Comisiones Especiales Investigadoras; y la introducción de la institución de las interpelaciones (Cordero, 2005: 522-526), aunque sin el respectivo voto de censura, tal como acontece en los regímenes parlamentarios.

Pero también, a través de la derogación de diversos instrumentos jurídicos establecidos en la Carta de 1980 en su versión original, expresión de la denominada «democracia protegida». Entre los cambios efectuados, destacan la eliminación de la institución de los senadores designados y vitalicios, poniendo término a la composición corporativista del Senado de la República, quedando, en adelante, conformado exclusivamente, a través de la técnica de la representación expresada por el sufragio universal (Pérez, 2005: 491-505). Asimismo, la supresión del rol entregado a las FF. AA. de ser "garantes del orden institucional de la República». A ello se sumó, el término a la inamovilidad de los comandantes en jefe de las Fuerzas Armadas, la modificación del Consejo de Seguridad Nacional, quedando ahora bajo tutela del poder civil. De esta manera, el COSENA, entre otras atribuciones, dejó de participar en la conformación del Tribunal Constitucional como del Senado (Verdugo, 2005: 679-709). Por tal motivo, se ha sostenido que las reformas de 2005 habrían puesto término de los denominados "enclaves autoritarios», suprimiéndolos en su totalidad (Nogueira, 2008: 367).

En este contexto de cambios de la forma de Estado, el Tribunal Constitucional también fue objeto de importantes reformas, tanto en su composición como también respecto de sus atribuciones. En efecto, el término de 
los denominados «enclaves autoritarios», se tradujo en la eliminación de los miembros elegidos por el Consejo de Seguridad Nacional —anteriormente señalada - y la consiguiente reestructuración de sus integrantes. De esta manera, el TC se vio aumentado de siete a diez miembros, tres designados por el presidente de la República; cuatro elegidos por el Congreso Nacional, correspondiéndole dos directamente al Senado, y los dos restantes a la Cámara de Diputados, previa ratificación de la Cámara Alta; y tres a la Corte Suprema. Destaca en este sentido, el término de la compatibilidad entre los ministros de la Corte Suprema y del Tribunal Constitucional, lo que no hacía sino que sembrar dudas respecto de su autonomía. Por su parte se aumentó la duración en sus cargos de ocho a nueve años, renovándose por parcialidades cada tres, manteniendo su inamovilidad, quedando, de esta forma, excluidos del impeachment o juicio constitucional.

De esta manera, se solucionaron dos críticas que se realizaban al Tribunal Constitucional en cuanto a su composición. En primer término, que el Consejo de Seguridad Nacional «designase ni más ni menos que dos abogados para el TC y que el Presidente y el Senado designaran un miembro cada uno. Y en segundo lugar, el rol desempeñado por la Corte Suprema de designar de entre sus miembros, mediante votación, a tres integrantes del TC». En efecto, "tales designaciones podían ser asimiladas, más bien, a verdaderos "cupos" del alto Tribunal al TC, porque estos miembros conservaban la calidad y el cargo en el alto Tribunal de justicia, desempeñando funciones, a la vez, en ambos órganos y perdiendo la condición de jueces constitucionales al dejar de ser ministros del alto Tribunal de Justicia» (Gómez, 2005: 655).

Asimismo, el TC fue objeto de importantes modificaciones en cuanto a sus atribuciones, ya que estas se vieron fuertemente aumentadas. Dentro de ellas, destacan, por un lado, el control sobre los autos acordados emanados de la Corte Suprema, las Cortes de Apelaciones y del Tribunal Calificador de Elecciones, atribución inédita en nuestra historia constitucional. $\mathrm{Al}$ respecto se destaca que esta enmienda «llena un vació en la práctica legal chilena, pues los AA no tenía control alguno y en ocasiones... excedía su competencia» (Gómez, 2005: 664). A ellas se suman la profundización del control de decretos supremos, en ejercicio de la potestad reglamentaria tanto ejecución como autónoma del presidente de la República (Cazor, 2006: 243).

Finalmente respecto al control de constitucionalidad de las leyes, se genera una importante modificación, a través del traspaso del control a posteriori por vía incidental y con efectos relativos, conocida como la «acción de inaplicabilidad», desde la Corte Suprema — prerrogativa existente desde la Constitución de 1925 - al Tribunal Constitucional. Pero también, por medio de la creación del control a posteriori por vía principal, y con efectos erga omnes, conocido como «acción de inconstitucionalidad», institución 
completamente novedosa en el constitucionalismo chileno. A juicio de la doctrina, estas modificaciones han dotado de un mayor grado de coherencia al sistema de justicia constitucional contemplado por la Constitución de 1980, al concentrar el control de constitucionalidad de las leyes, tanto preventivo como represivo en el TC, lo que incluso ha llevado a diversos autores a hablar de un «nuevo Tribunal Constitucional» (Ríos, 2005: 627).

\section{LA REFORMA DE 2005 Y LA ELIMINACIÓN DE LOS «ENCLAVES AUTORITARIOS": ¿̇UN NUEVO TRIBUNAL CONSTITUCIONAL?}

Diversos autores han sostenido que tras las reformas de 2005 persistirían de todas maneras instrumentos jurídicos expresión de una forma de Estado de «democracia protegida», pregonada por la Constitución de 1980 desde sus orígenes. Al respecto, se ha hablado de «la vieja—nueva Constitución de 1980-2005», ya que si bien se habrían introducido importantes cambios a nivel orgánico, persistirían los lineamientos dogmáticos originales. En efecto, la reforma de 2005 cierra en lo formal la transición a la democracia "al purgar la Constitución de sus "enclaves autoritarios", su estatuto fundamental transitorio, así como como la firma puesta en el texto por el gobernante de la época, la Junta de Gobierno y sus ministros». Sin embargo, «deja pendiente importantes cambios en su parte dogmática, (valores, principios, derechos fundamentales, y garantías), los componentes ideológicos (originalmente autoritarios, neoliberales, iusnaturalistas y lejanamente corporativistas) de una refundación autoritaria del capitalismo». De ahí que sostenga la necesidad de promover una reforma de «segunda generación» u "operación constituyente», de manera tal de «dotar a la Constitución de una legitimidad democrática mínima, concerniente a su origen e instituciones, y que abra su techo ideológico a todas las tradiciones del constitucionalismo, en especial, al constitucionalismo democrático y social» (Zúniga, 2007: 351-359).

Desde una perspectiva más crítica, también se ha sostenido que tras las citadas reformas se constataría la continuidad no solo de los aspectos dogmáticos originales previsto en la Constitución de 1980, sino que además, la persistencia de los denominados «enclaves autoritarios». Al respecto, sostiene que «se mantienen los lineamientos constitucionales neoliberales y autoritarios que dificultan la reemergencia del espíritu republicano que anima gran parte de nuestro devenir histórico desde la Independencia». En efecto, «el concepto de ciudadanía y de representación o inclusión política se insertan aún en la concepción original de democracia protegida, que se manifiesta en el sistema electoral excluyente de grupos políticos minoritarios, particularmente de la izquierda marxista». De ahí que se caracterice a la Constitución chilena como «gatopardo» — parafraseando el libro de Lampedusa - por cuanto «a pesar de 
todos los cambios que se le han hecho, permanecen igual en sus rasgos dogmáticos principales y en sus principios neoliberales y autoritarios». Por tal motivo destaca que "este rasgo "gatopardo" hace que la Constitución vigente sea la más reformada en la historia de Chile, y al mismo tiempo la más deficitaria en cuanto a su carácter democrático» (Ruiz-Tagle, 2006: 137).

En este contexto de cambios propiciados por la reforma de 2005, el control preventivo de constitucionalidad no quedó incólume, ya que también fue objeto de modificaciones, aunque, paradojalmente, no para restringir su alcance, sino que por el contrario, para ampliar su ámbito de aplicación. En efecto, a la modalidad obligatoria se añadió - como vimos anteriormenteel control de los tratados internacionales cuando versen sobre materias propias de ley orgánica constitucional (LOC). La razón de ser de esta modificación estuvo dada por los problemas provocados por la sentencia dictada por el TC con ocasión del control preventivo facultativo del Convenio 169 sobre Pueblos Indígenas y Tribales en Países Independientes, adoptado por la Organización Internacional del Trabajo (García, 2007: 470).

De esta manera, el control preventivo conserva bastante continuidad, confirmando el sistema diferenciado de quorum — supramayoritario en el caso de las LOC - entre las normas de rango legal. Por tal motivo, es posible sostener que la reforma de 2005 no logró suprimir el diseño normativo de la forma de Estado establecida en la Carta de 1980, persistiendo en su seno los rasgos de "democracia protegida", temerosa de un eventual desborde gubernamental, en este caso, en el marco de la función legislativa.

En este contexto, diversos autores han dado cuenta de la anomalía democrática de este tipo de normas de rango legal, expresión de la «democracia protegida" establecida en la Constitución de 1980, y persistente hasta nuestros días. Las críticas se han centrado, principalmente, en los altos quorum exigidos para su aprobación, modificación y derogación, que obliga a los órganos colegisladores a lograr verdaderas supermayorías para poder legislador sobre ellas.

Como queda en evidencia, las LOC son un tipo especial de ley, conocidas como «leyes reforzadas», ya que su especificidad está dada por su mayor rigidez formal respecto de las leyes ordinarias, como por las materias que le correspondan regular (Otto, 1998: 112). En el marco de la forma de gobierno presidencialista, las LOC obligan al primer mandatario a contar con verdaderas supermayorías en el Congreso Nacional si es que desea sacar adelante un determinado proyecto de ley que importe materias de LOC. Y a contrario sensu, entregan a la oposición parlamentaria un importante instrumento jurídico que termina morigerando demasiado su carácter minoritario, otorgándole un verdadero poder de veto. $\mathrm{Al}$ respecto, se ha señalado que «...la regla de supramayoría le quita flexibilidad a la operación del Estado y del gobierno. Exige un consenso demasiado extendido para dictar leyes» (Sierra, 2011: 60). 
De igual manera, que las LOC representan «una de las manifestaciones del interés del constituyente de 1980 por limitar la capacidad reguladora de la ley». Como consecuencia de aquello, estas terminan enervando «el esfuerzo reformista de las mayorías simples» (Zapata, 2011: 402).

En este sentido, se ha sostenido que sus altos quorum «son el equivalente funcional de lo que en otras democracias representa la propia Constitución». Ellas son expresión de "una forma de "democracia protegida"», toda vez que su establecimiento buscó «blindar» aspectos básicos «de una concepción de la política, la economía y la sociedad contra el riesgo de que fuera luego desmantelada por la democracia» (Jiménez, Marshall y Muñoz, 2013: 359-393).

De esta manera, el control preventivo obligatorio guarda importantes diferencias con el facultativo, toda vez que - desde el punto de vista del diseño normativo- no estaría en función de garantizar el predominio del presidente de la República por sobre el Congreso Nacional. Como hemos argumentado a lo largo de este trabajo, respondería a un objetivo mayor, coherente con la concepción de forma de Estado prevista por la actual Carta Fundamental, ya que estaría destinado a evitar el desborde gubernamental en la función legislativa, respecto de aquellas materias que el constituyente del ochenta, decidió excluir de la voluntad de las mayorías políticas.

\section{CONCLUSIONES}

En principio, es posible apreciar múltiples semejanzas entre el Tribunal Constitucional albergado en la Constitución de 1925, a través de la reforma de 1970, con el establecido en la Constitución de 1980, particularmente, en lo que dice relación con sus atribuciones de control preventivo facultativo. Sin embargo, estas semejanzas no alcanzarían para trazar una clara continuidad entre ambos órganos, por cuanto, según pudimos analizar, el TC de 1970 se enmarcó dentro de un proceso de cambio constitucional mayor, destinado a fortalecer las prerrogativas del presidente, situándolo como un órgano destinado a hacer eficaces dichas atribuciones, establecidas en claro desmedro del Congreso Nacional.

En cambio, en el TC establecido por la Constitución de 1980, si bien existiría la intención de fortalecer al primer mandatario en detrimento del Parlamento — plasmado a través de la denominada «democracia autoritaria»-, ello conviviría con el temor a eventuales desbordes gubernamentales, tal como habría acontecido, según la visión de la época, durante el gobierno de la Unidad Popular. De ahí que los constituyentes de 1980 añadieron diversos instrumentos jurídicos —expresión de la llamada «democracia protegida»— de manera tal de evitar un eventual desborde gubernamental, tras el período 
de restauración democrática, configurando, de esta manera, aspectos que forman parte del diseño normativo del control preventivo, particularmente, el obligatorio.

En este sentido, la Carta de 1980 fue pensada para que, una vez restablecida la democracia, existiera un marco rígido por el cual debía moverse el juego institucional. Ello es posible apreciarlo, en el caso del TC, en las modificación del control preventivo facultativo, al cual se le añadió los proyectos de reforma constitucional, al tiempo que se estableció un control a priori de carácter obligatorio, de una nueva categoría de norma de rango legal — las LOC— las que estuvieron destinadas a proyectar los lineamientos constitucionales en el ámbito de la legislación. Para ello, se estableció que estas, además de requerir de un quorum supramayoritario para su aprobación, modificación o derogación, fuesen objeto de control preventivo de carácter obligatorio por parte del TC.

Estos lineamientos persistieron por cerca de quince años luego del retorno a la democracia en 1990, hasta que por medio de la reforma constitucional de 2005 se introdujeron importantes cambios a la Carta de 1980. Ellos estuvieron destinados, por una parte, a poner término de los denominados «enclaves autoritarios» persistentes en su texto, y conformadores de una particular concepción de la forma de Estado, expresión de la «democracia protegida», como también a diversas atribuciones destinadas a morigerar la «democracia autoritaria», entregando mayores herramientas de contrapeso al Congreso Nacional — particularmente a la Cámara de Diputados — frente al primer mandatario.

Estos cambios fueron de la mano con el reforzamiento de las atribuciones del TC. Pese a que múltiples autores calificaron estos cambios como la instauración de una nueva justicia constitucional, es posible apreciar la existencia de bastantes continuidades con el TC establecido por la Carta del ochenta. En efecto, el control preventivo no solo es mantenido, sino que es fortalecido, al añadirse dentro de las normas objeto de control obligatorio, los tratados internacionales que versen sobre materias de LOC. Por su parte, se potencian aún más sus prerrogativas respecto del ejercicio de la potestad reglamentaria del presidente, al tiempo que se establece el control represivo de los autos acordados emanados de los Tribunales Superiores de Justicia y del Tribunal Calificador de Elecciones.

De esta manera, es posible argumentar, desde el punto de vista normativo, que pese a las reformas constitucionales de 2005 suprimieron la casi totalidad de los denominados «enclaves autoritarios», estas no habrían alcanzado a generar un nuevo Tribunal Constitucional, sino que, por el contrario, habrían profundizado sus lineamientos iniciales articulados bajo una particular concepción de la forma de Estado, desconfiada de las instituciones democráticas, temerosa de un eventual desborde gubernamental, en el marco de la función legislativa. 


\section{Bibliografía}

Andrade, C. (1996). Tribunal Constitucional. Cuadernos de Análisis Jurídico, 31, $277-$ 309.

Aragón, M. (1987). El control como elemento inseparable del concepto de Constitución. Revista Española de Derecho Constitucional, 19, 15-52.

Barros, R. (2005). La Junta Militar. Pinochet y la Constitución de 1980. Santiago: Editorial Sudamericana.

Bertelsen, R. (1969). Control de constitucionalidad de la ley. Santiago: Editorial Jurídica de Chile.

Bulnes, L. (1984). La Ley Orgánica Constitucional. Revista Chilena de Derecho, 11 (2-3), 227-239.

Carmona, C. (2014). Las reformas a la Constitución entre 1989 y 2013. Revista de Derecho Público, (número especial), 57-81.

Carrasco S. (1987). Alessandri. Su pensamiento constitucional. Reseña de su vida pública. Santiago: Editorial Jurídica de Chile.

— (2002). Génesis y vigencia de los textos constitucionales chilenos. Santiago: Editorial Jurídica de Chile.

Cazor, K. (2006). Actual marco atributivo del Tribunal Constitucional en el control de los decretos supremos presidenciales. Estudios Constitucionales, 1, 233-240.

Comisión de estudios de la nueva Constitución Política de la República. (1978). Anteproyecto constitucional y sus fundamentos. Santiago: Editorial Jurídica de Chile.

Cordero, E. (2005). La facultad fiscalizadora de la Cámara de Diputados. En F. Zúñiga (coord.). Reforma constitucional. Santiago: Lexis Nexis.

Correa, S. et al. (2005). Historia del siglo XX chileno: balance paradojal. $3^{\mathrm{a}}$ ed. Santiago: Sudamericana.

Cristi, R. (2000). El pensamiento político de Jaime Guzmán. Autoridad y Libertad. Santiago: LOM.

Cumplido, F. (1964). Inconstitucionalidad de la ley. Revista de Derecho y Ciencias Sociales, $128,70-71$.

Fermandois, A. y García, J. (2009). Origen del presidencialismo chileno: reforma constitucional de 1970, ideas matrices e iniciativa legislativa exclusiva. Revista Chilena de Derecho, 36 (2), 281-311. Disponible en: https://doi.org/10.4067/S071834372009000200004.

Frei Montalva, E. (1970). La Reforma constitucional en su contexto histórico. En E. Frei Montalva et al. Reforma constitucional de 1970. Santiago de Chile: Editorial Jurídica de Chile.

García Barzelatto, A. (2007). Informe en Derecho. Control de constitucionalidad de los tratados internacionales con especial referencia al control represivo. Estudios Constitucionales, 1, 469-480.

Garretón, M. (1989). La posibilidad democrática chilena. Santiago: FLACSO.

Godoy, O. (2003). Parlamento, presidencialismo y democracia protegida. Revista de Ciencia Política, 23 (2), 7-42. 
Gómez, G. (1996). El control de constitucionalidad y el Tribunal Constitucional de 1980. Cuadernos de Análisis Jurídico, 31, 3-274.

— (2005). La reforma constitucional a la jurisdicción constitucional. El nuevo Tribunal Constitucional chileno. En F. Zúñiga (coord.). Reforma constitucional. Santiago: Lexis Nexis.

Góngora, M. (2006). Ensayo histórico sobre la noción de Estado en Chile en los siglos XIX y XX. $9^{a}$ ed. Santiago: Universitaria.

Guzmán, J. (1979). La Constitución Política. Revista Chilena de Derecho, 6 (1-4), 53-78.

Heise, J. (1974). Historia de Chile. El periodo parlamentario 1861-1925, Tomo I, Fundamentos histórico-culturales del parlamentarismo chileno. Santiago: Editorial Andrés Bello.

Jiménez, G., Marshall, P. y Muñoz, F. (2013). La debilidad de las supermayorías. Revista de Derecho, 16 (2), 359-393.

Meléndez, F. (2010). Las prácticas partidistas bajo la Constitución de 1925: la relativización del presidencialismo chileno. Revista de Estudios Parlamentarios Hemiciclo, 3, 7-26.

Merryman, J. (1995). Sistemas legales en América Latina y Europa. Tradición y Modernidad. Santiago: Fondo de Cultura Económica.

Nogueira, H. (1996). El Tribunal Constitucional chileno. Cuadernos de Análisis Jurídico, 31, 311-336.

(2008). La evolución político-constitucional de Chile 1976-2005. Estudios Constitucionales, 2, 325-370. Disponible en: https://doi.org/10.4067/S071852002008000100011.

Otto, I. (1998). Derecho Constitucional. Sistema de fuentes. Barcelona: Ariel.

Paredes, F. (2011). Justicia constitucional y democracia: sello de constitucionalidad en el control preventivo obligatorio (Tribunal Constitucional). Revista de Derecho, 24 (1), 165-172. Disponible en: https://doi.org/10.4067/S0718-09502011000100009.

Pérez, R. (2005). Senado y reforma constitucional: modificación al artículo 45 de la Constitución de 1980. En F. Zúñiga (coord.). Reforma constitucional. Santiago: Lexis Nexis.

Pinochet, A. (1978). Normas para la nueva Constitución. En Comisión de Estudios de la Nueva Constitución Política de la República. Anteproyecto constitucional y sus fundamentos. Santiago: Editorial Jurídica de Chile.

Ríos, L. (2005). El nuevo Tribunal Constitucional. En F. Zúñiga (coord.). Reforma constitucional. Santiago: Lexis Nexis.

Ruiz-Tagle, P. (2006). El constitucionalismo chileno: entre el autoritarismo y la democracia. En R. Cristi y P. Ruiz-Tagle. La República en Chile. Teoría y práctica del constitucionalismo republicano. Santiago: LOM.

Sierra, L. (2011). La supramayoría en la potestad legislativa chilena como anomalía democrática. En L. Sierra y L. Mac-Clure. Frente a la mayoría: leyes supramayoritarias y Tribunal Constitucional en Chile (pp. 12-168). Santiago: Centro de Estudios Públicos, Corporación de Estudios para Latinoamérica, Libertad y Desarrollo, Proyecta América. 
Silva Bascuñán, A. (2003). Tratado de Derecho Constitucional, Tomo IX. 2a ed. Santiago: Editorial Jurídica de Chile.

Silva Cimma, E. (2008). El Tribunal Constitucional de Chile (1971-1973). 2a ed. Santiago: Cuadernos del Tribunal Constitucional.

Tapia Valdés, J. (1960). La técnica legislativa. Santiago: Editorial Jurídica de Chile.

Urzúa Valenzuela, G. (1992). Historia politica de Chile y su evolución electoral (desde 1810 a 1992). Santiago: Editorial Jurídica de Chile.

Verdugo, M. (2005). Notas a la reforma constitucional en lo que atañe a las Fuerzas Armadas y Consejo de Seguridad Nacional. En F. Zúñiga (coord.). Reforma constitucional. Santiago: Lexis Nexis.

Zapata, P. (2011). Justicia constitucional. Teoría y práctica en el Derecho chileno y comparado. Santiago: Editorial Jurídica de Chile.

Zúñiga, F. (2002). Elementos de Derecho Constitucional, Tomo II. Santiago: Universidad Central de Chile.

— (2007). Vieja-nueva Constitución. Estudios Constitucionales, 1, 349-370. 